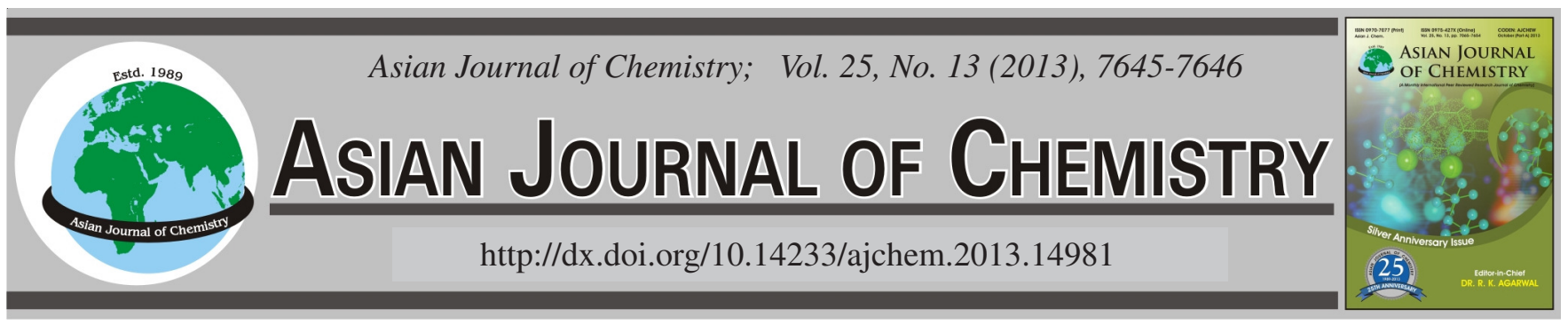

NOTE

\title{
Study on the Tensile and Impact Properties of Bagasse Flour/ Recycled High-Density Polyethylene Composite
}

\author{
Amir Hooman Hemmasi
}

Department of Wood and Paper Engineering, Science and Research Branch, Islamic Azad University, Tehran, Iran

Corresponding author: E-mail: h_hemmasi@yahoo.com

(Received: 15 December 2012;

Accepted: 5 July 2013)

AJC-13776

\begin{abstract}
In this research, the possibility of using high percentage of lignocellulosic fibers in making natural fiber-thermoplastic composite was studied. For this purpose, the bagasse flour was mixed with recycled high-density polyethylene at three levels of 30, 40 and 50 wt $\%$. MAPE coupling agent was also used in $3 \mathrm{wt} \%$. The results showed that with increasing bagasse flour percentage, tensile strength improved, but impact strength decreased.

Key Words: Bagasse flour, Tensile strength, Recycled high-density polyethylene, Impact strength.
\end{abstract}

Sugarcane bagasse is an important agricultural crop in the Iran. Approximately 4.3 million tons of bagasse is produced annually in Iran and the production is mainly centered in the southwestern province of Khuzestan ${ }^{1}$. Many composite items comprising natural fibers and plastic are in use in many countries to make various products such as interior and exterior automotive parts, floorings, constructional/non-constructional timbers, confined doors and windows, furniture parts, packing industries, children's playgrounds, enclosures, production of extruded profiles, kitchen cabinets, etc. ${ }^{2}$. Bagasse is the residue after sugarcane stalks being crushed for sap extraction. Approximately $32 \%$ of bagasse is produced for per metric ton of processed sugar cane ${ }^{3}$. Meanwhile, it is one of the most important agricultural fibers and lignocelluloses wastes, which is regularly cultivated in tropical countries, namely Brazil, India, Cuba and some areas of Iran $(\mathrm{FAO})^{4}$. Today, bagasse is used more sustainably as a major raw material for fuel as well as for pulp and paper production in addition to being a reinforcement material in value-added composite panel production ${ }^{3}$. A review of literature shows that there are a limited number of useful studies on the use of bagasse fibers for composite production $^{5-7}$. However, it must be noticed that higher amount of the filler material will reduce impact strength ${ }^{8,9}$. Therefore, the aim of this study was to investigate the effect of bagasse fiber loading in experimental bagasse type of natural fiberplastic composites on their mechanical properties and then the parameters such as tensile and impact strength were evaluated.
Bagasse was collected from the supplied by Choob Plastic DEZ Co, 100-mesh bagasse flour was used as filler. Recycled High-Density polyethylene (rHDPE) was provided as granules by Arak Petrochemical Company. The rHDPE has melt flow indices of $23.037 \mathrm{~g} / 10 \mathrm{~min}$ at $190{ }^{\circ} \mathrm{C}$ and density of $0.956 \mathrm{~g}$ $\mathrm{cm}^{-3}$. Maleic anhydride grafted polyethylene (PP-g-MA) provided by Solvay with trade name of Priex 20070 (MFI = 7 $\mathrm{g} / 10 \mathrm{~min}$, grafted maleic anhydride $0.1 \mathrm{wt}$. \%) was used as coupling agent.

Before the preparation of samples, bagasse flour was dried in an oven at $65 \pm 5{ }^{\circ} \mathrm{C}$ for $24 \mathrm{~h}$. Then for manufacturing bagasse-rHDPE composites, bagasse flour, recycled highdensity polyethylene and coupling agent based on Table-1 were weighted individually and then mixed in mixer equipment at rotation speed of $1500 \mathrm{rpm}$ in order to get a homogenous mixture. Then blended in a counter-rotating twin-screw extruder (Dr. Collin System). The compounded materials were then grinded to prepare the granules using a pilot-scale grinder. The mix was removed from the mixing bowl, cooled in water and granulated into pellets. The pellets were dried at $105^{\circ} \mathrm{C}$ for $24 \mathrm{~h}$ before injection molding. Test specimens were prepared by an injection molding machine according to standard ASTM D 638.

Measurement of mechanical properties: Tensile test was run according to ASTM D 638 standard. Impact test was also accomplished according to ASTM D 256 standard. Data analysis followed a completely randomized procedure by using statistical software of SPSS in terms of factorial test. Finally, 
TABLE-1

WEIGHT PERCENTAGES FOR COMPONENTS OF NATURAL FIBER-PLASTIC COMPOSITE IN DIFFERENT TREATMENTS

\begin{tabular}{cccc}
\hline $\begin{array}{c}\text { Treatment } \\
\text { no. }\end{array}$ & $\begin{array}{c}\text { Bagasse flour } \\
(\%)\end{array}$ & $\begin{array}{c}\text { rHDPE } \\
(\%)\end{array}$ & $\begin{array}{c}\text { MAPE } \\
(\%)\end{array}$ \\
\hline 1 & 30 & 70 & 3 \\
2 & 40 & 60 & 3 \\
3 & 50 & 50 & 3 \\
\hline
\end{tabular}

comparing and grouping of the means were implemented through Duncan test at $95 \%$ confidence level.

Tensile strength: Analysis of variance revealed that the effect of bagasse flour on tensile strength of natural fiber-plastic composites was significant at the $95 \%$ confidence level. The Duncan table classified the means obtained from measuring tensile strength of natural fiber-plastic composites, at three different levels of bagasse flour (30, 40 and $50 \mathrm{wt} \%)$ and coupling agent ( $3 \mathrm{wt} \%$ ) within two distinctive groups. Various parameters influence the tensile strength of fiber-reinforced composites including the fiber aspect ratio, fiber content, mixing temperatures. It is observed that by increasing the fiber content from 30 to $50 \mathrm{wt}$. \%, the tensile strength was increased (Fig. 1). The experimental results show that the tensile strength of composite resulted in an optimum value at certain fiber content. In this study, the optimum fiber content is $50 \%$. The comparison between samples indicated that composites which enjoyed $30 \%$ bagasse fiber had lower tensile strength (18.383 $\mathrm{MPa})$ than the $50 \%$ ones $(19.347 \mathrm{MPa})$.

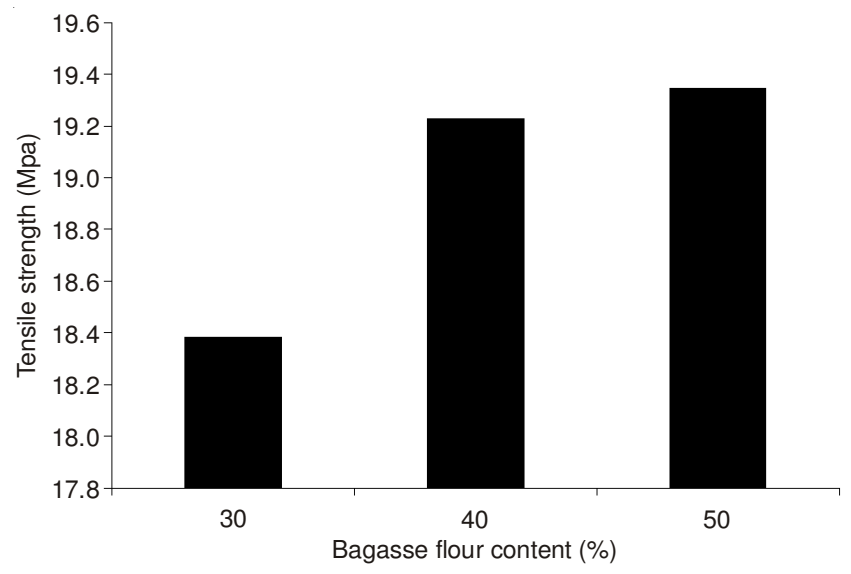

Fig. 1. Effect of bagasse flour on tensile strength

Tensile strengths of bagasse fiber-rPE composites are severely dependent on the interfacial quality between the two phases of the composite, since the transfer of stress from the base material (matrix phase) to the fibers (reinforcement phase) occurs within this zone. Principally, the key role of the matrix phase is to hold fibers and shift loads to the secondary phase, whereas the major role of the secondary phase is to reinforce the matrix physically and mechanically. Therefore, increasing the amount of the filler materials will enhance the extent of tolerable stress in the composite due to its existing reinforcement phase ${ }^{10,11}$. This is in accordance with the results obtained by Tehrani et al. ${ }^{5}$, Ashori and Nourbakhsh ${ }^{6}$.

Impact strength: The variance analysis showed that the effect of bagasse flour on impact strength of natural fiberplastic composites was significant at the $95 \%$ confidence level.
The Duncan table divided the means obtained from measuring impact strength of natural fiber-plastic composites at three different levels of bagasse flour (30, 40 and $50 \mathrm{Wt} \%)$ into three distinct groups. The amount of impact strength for the sample containing $50 \mathrm{wt} \%$ bagasse flour was less than samples of other bagasse percentages (Fig. 2). The presence of lignocelluloses material (wood flour and natural fibers) creates areas of stress concentration and crack initiation. The impact strength will be decreased by the addition of further filler materials. On the other hand, the presence of wood flour will increase the energy absorbed by bagasse flour-rHDPE composites. As a result, the addition of lignocelluloses filler will lead to higher stress concentration areas and initiate crack growth ${ }^{12,13}$. This is in accordance with the findings of Tehrani et al., ${ }^{5}$ Ashori and Nourbakhsh ${ }^{6}$.

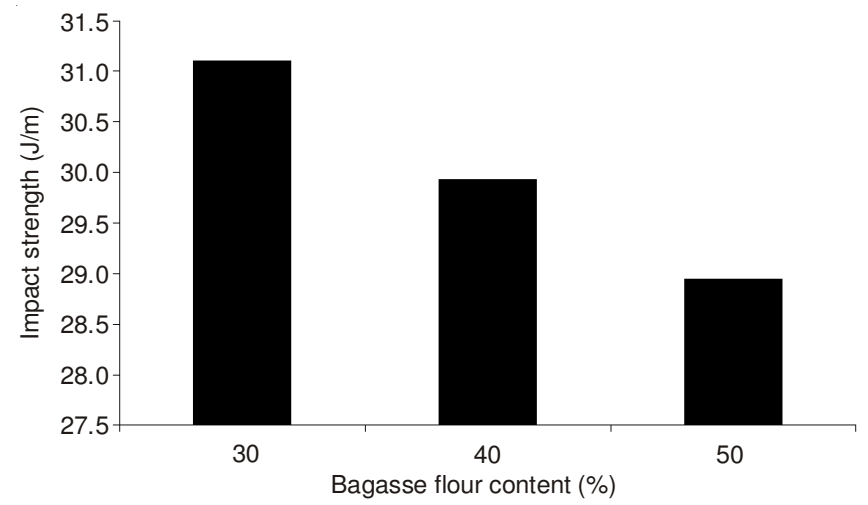

Fig. 2. Effect of bagasse flour on impact strength

\section{Conclusion}

(1) The tensile strength of the composite improved with increasing bagasse flour content due to the improvement of interface bond between the fiber and matrix.

(2) By increasing bagasse up to $50 \%$, the impact strength slightly decreased.

\section{REFERENCES}

1. G. Najafi, B. Ghobadian, T. Tavakoli and T. Yusaf, Renew. Sustain. Energy, 13, 1418 (2009).

2. P. Rowell, Advanced Composites Manufacturing, John Wiley \& Sons, New York (2002).

3. S.C. Lee and M. Mariatti, Mater. Lett., 62, 2253 (2007).

4. FAO Statistics, Major Food and Agricultural Commodities and Producers, Online at http://www.fao.org (consulted January 25, 2006).

5. B. Tehrani, A. Omidvar and A. Ramtin, Scient. Res. J. Wood Paper Sci., 23, 178 (2008).

6. A. Ashori and A. Nourbakhsh, Waste Manage., 30, 680 (2009).

7. J.Z. Lu, Q. Wu, I.I. Negulescu and Y. Chen, J. Appl. Polym. Sci., 102, 5607 (2006).

8. Y.Y. Zhou and S. Li, Asian J. Chem., 25, 2767 (2013).

9. M. Tajvidi, M. Chaharmahali and S.K. Najafi, J. Polym. Composites, 29, 606 (2008).

10. A. Nourbakhsh, K. DoustHosseini, A.J. Latibari and A. Hosseinzadeh, J. Nat. Resour. Tehran Univ., 57, 765 (2004).

11. N.M. Stark and R.E. Rowland, Wood Fiber Sci., 35, 167 (2003).

12. M. Tajvidi, Ph. D. Thesis, Studying Engineering and Viscoelastic Properties of Composites Made from Thermoplastic Polymers and Natural Fibers Using Dynamic-Mechanic Analysis, Tehran University, Tehran, Iran (2003).

13. K. Oksman and H. Lindberg, J. Appl. Polym. Sci., 68, 1845 (1998). 